
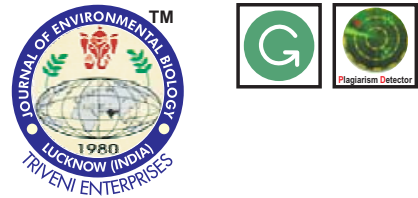

\title{
Detection of endospore producing Bacillus species from commercial probiotics and their preliminary microbiological characterization
}

\section{Authors Info}

J. Jezewska-Frackowiak', K. Seroczynska², J. Banaszczyk ${ }^{3}$, D. Wozniak ${ }^{4}$, M. Skowron ${ }^{5}$, A. Ozog ${ }^{6}$, A. Zylicz-Stachula', T. Ossowski and P. M. Skowron ${ }^{9 *}$ ${ }^{1,6,7,9}$ Department of Molecular Biotechnology, Faculty of Chemistry, University of Gdansk, 80-308, Gdańsk, Poland

${ }^{2,3.4}$ GRUPA INCO S.A., 00-519, Warszawa, Poland

${ }^{5}$ BioVentures Institute Ltd., 60-141, Poznan, Poland

${ }^{8}$ Department of Analytical Chemistry, Faculty of Chemistry, University of Gdansk, 80-308, Gdańsk, Poland

*Corresponding Author Email : piotr.skowron@ug.edu.pl

Key words

Bacillus sp.

Industrial probiotics

MALDI-TOF bacteria

Microbiological characterization

\section{Publication Info}

Paper received : 07.10 .2016

Revised received : 28.03.2017

Re-revised received : 24.04.2017

Accepted : 24.06.2017

\begin{abstract}
Aim : The main objective of the study was to characterize a mixture of bacterial species, found in commercial probiotic preparation and originally designed for cleaning, biodegradation and wastewater treatment.

Methodology : Lyophilized preparation of environmental strains was microbiologically characterized to determine the growth temperature range, $\mathrm{pH}$ resistance and boiling temperature survivability. Gram staining and Wirtz's spores staining were performed for microscopic estimation of cell morphology and sporulation. The MALDI-TOF mass spectrometry method was used to identify bacterial species found in the preparation.

Results : The composition of probiotic bacterial species, isolated from commercial lyophilized preparation, exhibited wide range of growth temperatures, extreme boiling survivability and wide range of $\mathrm{pH}$ survivability. The isolated species belonged to Bacillus genus, Gram positive and sporulating rods. MALDITOF bacterial identification method was carried out for detection of four non-pathogenic, environmental, closely related strains: Bacillus subtilis, Bacillus mojavensis, Bacillus vallismortis and Bacillus pumilus.

Interpretation : The endospore producing environmental Bacillus species were detected in commercial probiotics and preliminary characterised. The results of the present study, point out the possible applications of the described Bacillus sp. mixture in health, food and cleaning technologies, involving high temperatures or high/low $\mathrm{pH}$ processes.
\end{abstract}
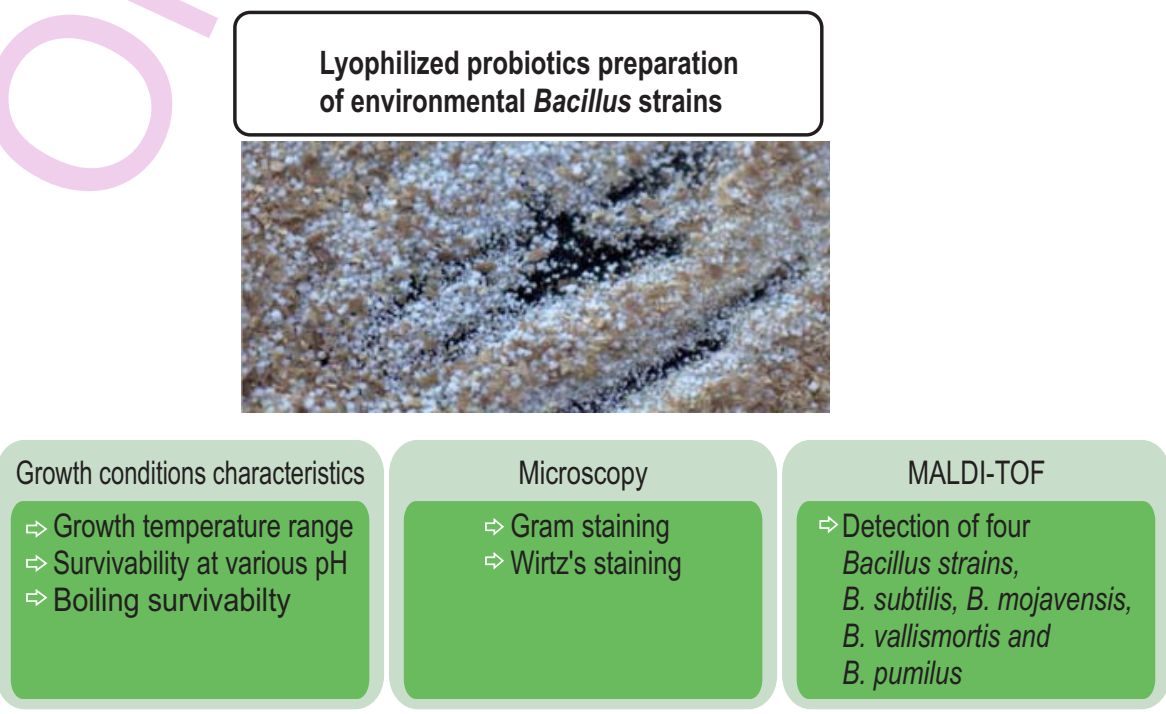


\section{Introduction}

Probiotics are microorganisms conferring health benefits to both humans or animals, by the mean of pathogenic flora replacement, production of vitamins, immune system stimulation, generation of a chemical/biological environment for gastrointestinal tract functioning (Quigley, 2010; Castelazzi et al., 2013; Plaza-Diaz et al., 2014). Among them are bacteria naturally residing in the gastro intestinal tract of human, such as Lactobacillus sp., and allochthonous or bimodal ones like certain Bacillus sp., capable of colonizing the gastrointestinal tract, while being typically environmental microflora. The use of probiotics has become a mainstream application in health, food and cleaning technologies with a number of specialized probioticbased products.

Studies conducted on animal models have shown positive effects of the bimodal probiotic Bacillus sp. These include the protective activity of Bacillus subtilis against Salmonella enteritidis or pathogenic Escherichia coli infection in poultry (La Ragione and Woodward, 2001; La Ragione et al., 2001; Thirabunyanon et al., 2011). Bacillus sp. are also beneficial in establishing rumen microflora in calves, speeding up transition from liquid to solid feed and reducing diarrheal syndrome (Jenny et al., 1991). In humans, the benefits of Bacillus sp. probiotics include reduction of undesired bacteria (Klebsiella, Proteus, Shigella, Pseudomonas, Escherichia coli) in urine of elderly patients with slow/static urine flow (Meroni et al., 1983) observed in successful clinical trials. The application of probiotics prevents antibiotic-associated diarrhea in children (La Rosa et al., 2003). The use of probiotics in patients with irritable bowel syndrome has been reported effective and safe therapy (Urgesi et al., 2013). Bacillus sp. probiotics can exercise anti-oxidative stress in humans, including DNA-protective effect (Prazdnova et al., 2015). Recent studies have shown the probiotic ability to affect immunity and inflammatory genes expression in gastrointestinal tract and reduction of inflammatory diseases in gut and liver (Plaza-Diaz et al., 2014).

Characterization of bacteria in probiotics may enhance knowledge concerning bacterial species content and conditions of the probiotics survival, which is crucial in their applications and implications for assessing potential advantages and drawbacks when used in human- or environment- related industries. Hence present study was undertaken to characterize the bacteria in commercial probiotics BPB-100 and BACILOX®XL 100X.

\section{Materials and Methods}

The commercial preparation BPB-100 and BACILOX® XL 100x from Osprey Biotechnics (Sarasota, FL, USA) with the initial CFU values (given by the manufacturer). $\geq 100 \times 10^{9} \mathrm{CFU} \mathrm{g}{ }^{-1}$ and $\geq 5.5 \times 10^{9} \mathrm{CFU} \mathrm{ml} l^{-1}$, respectively, were used for isolation and characterization of probiotics mixture, namely Bacillus subtilis, Bacillus mojavensis, Bacillus vallismortis and Bacillus pumilus.
Soy peptone was procured from Scharlau Microbiology (Barcelona, Spain), while other reagents were procured from Sigma-Aldrich (St Louis, MO, USA). Probiotics preparation for subsequent microbiological tests was suspended in LB medium in 1:5 mass ratio, resulting liquid sample for further analyses. Probiotic sample was plated onto solid media: LA, 2YT and TB. Growth temperature range was tested on LA medium and observed after $48 \mathrm{hrs}$. Survivability at various $\mathrm{pH}$ was tested by inoculating the probiotic bacteria liquid sample in 1:100 ratio into the fresh LB medium of $\mathrm{pH}$ values ranging from 1-13 and followed by incubation at room temperature for $24 \mathrm{hrs}$. After incubation, $100 \mu \mathrm{l}$ of samples were plated on the LA agar and incubated further for $24 \mathrm{hrs}$ at $37^{\circ} \mathrm{C}$. The boiling survivability was assayed in LB medium at $100^{\circ} \mathrm{C}$, time course samples were taken and streaked on the LAmedium for $24 \mathrm{hrs}$ at $37^{\circ} \mathrm{C}$ incubation.

Microbiological properties were determined using Gram staining and spores Wirtz's staining with malachite green and safranin (Bartholomew and Mittwer, 1952; Hamouda et al., 2002). Slide glass preparations were observed under Olympus CX21FS1 light microscope at 1200x magnification.

For the MALDI-TOF mass spectrometry, single colonies on LA were isolated after $24 \mathrm{hrs}$ incubation at $37^{\circ} \mathrm{C}$ and subjected to MALDI Biotyper (Bruker Daltonics, Billerica, MA, USA) at Laboratoria Medyczne Bruss (Gdynia, Poland). Resulting spectra was compared with intracellular proteins profile databases for microbiological species (Azarko and Wendt, 2011).

\section{Results and Discussion}

The commercial probiotics were selected for the study. The detailed microbiology information concerning products are generally not provided by the manufacturers, while probiotics may have substantial impact on the environment and/or human health. The use of probiotics is increasingly popular, thus the presented independent study is useful when planning health, food, cleaning related or environmental usage of probiotics.

Analyses of both Bacilox® probiotics, covering an estimation of the bacterial growth conditions, microscopic examination and MALDI-TOF, showned that preparations contained the same mixture of meso- to thermophilic bacterial species/strains belonging to Bacillus genus.

To characterize the probiotics microbiological composition, single colonies from LA medium (3 per each morphological type) were subjected to MALDI-TOF assay. This method determines the identity of the microorganism (Azarko and Wendt, 2011), as microbial protein spectrum is unique for genus/species. The assay allowed to differentiate four closely related Bacillus species: Bacillus subtilis, Bacillus mojavensis, Bacillus vallismortis, Bacillus pumilus, residing the same lyophilized preparation sample. Results were reinforced by the analysis with standard microbiological assays: Gram staining and 
Table 1 : Growth conditions of the bacterial population in the probiotic preparation containing Bacillus subtilis, Bacillus pumilus, Bacillus vallismortis and Bacillus mojavensis

\begin{tabular}{|c|c|}
\hline \multicolumn{2}{|c|}{ Growth temperature range } \\
\hline Temperature $\left({ }^{\circ} \mathrm{C}\right)$ & Growth intensity \\
\hline 17 & - \\
\hline 18 & + \\
\hline 20 & ++ \\
\hline 30 & +++ \\
\hline 37 & +++ \\
\hline 45 & +++ \\
\hline 51 & +++ \\
\hline 53 & +++ \\
\hline 55 & ++ \\
\hline 56 & + \\
\hline 57 & - \\
\hline \multicolumn{2}{|c|}{ Survivability at various $\mathrm{pH}$} \\
\hline $\mathrm{pH}$ & Growth intensity \\
\hline 1 & $+/-$ \\
\hline 2 & + \\
\hline 3 & +++ \\
\hline 4 & +++ \\
\hline 5 & +++ \\
\hline 6 & +++ \\
\hline 7 & +++ \\
\hline 8 & +++ \\
\hline 9 & +++ \\
\hline 10 & +++ \\
\hline 11 & ++ \\
\hline 12 & + \\
\hline 13 & - \\
\hline \multicolumn{2}{|c|}{ Boiling survivability $\left(100^{\circ} \mathrm{C}\right)$} \\
\hline Time & Growth intensity \\
\hline $0 \mathrm{~min}$ & $+++>>-$ \\
\hline $5 \mathrm{~min}$ & +++ \\
\hline $10 \mathrm{~min}$ & +++ \\
\hline $20 \mathrm{~min}$ & +++ \\
\hline $40 \mathrm{~min}$ & ++ \\
\hline $1.5 \mathrm{hr}$ & ++ \\
\hline $4 \mathrm{hr}$ & + \\
\hline $18 \mathrm{hr}$ & + \\
\hline
\end{tabular}

Growth intensity rating of probiotic bacteria colonies after $24 \mathrm{hrs}$ incubation at $37^{\circ} \mathrm{C}$ on LA agar:- no growth (no colonies); + few bacterial colonies; ++ numerous bacterial single colonies visible; agar partially covered with bacterial film;+++ single coloniesdifficult to distinguish, agar mostlycovered with bacterial film

spores Wirtz's staining (Fig. 1), growth temperature range (Table 1, Fig. 2), pH resistance and boiling temperature resistance (Table 1). All the results corroborated the published characteristics of four Bacillus sp. determined. These bacteria are closely related (Roberts et al., 1994; Roberts et al., 1996), Bacillus vallismortis and Bacillus mojavensis differ from Bacillus subtilis in fatty acids composition, whereas being genetically similar in their DNA sequences, proteome conservation and genomes architecture (Earl et al., 2012). High similarity of
Bacillus subtilis and Bacillus pumilus is supported by $16 \mathrm{~S}$ rRNA gene sequence analysis - out of 5 Bacillus groups based on this phylogenetic analysis, Bacillus pumilus belongs to the Bacillus subtilis group (Berkeley et al., 2008). The four identified strains formed distinct morphological colony variants with Bacillus vallismortis and Bacillus mojavensis being similar, whereas Bacillus subtilis and Bacillus pumilus were different in terms of colony morphology, size and growth rate (Fig. 1). The temperature $37^{\circ} \mathrm{C}$ was the most differentiating, thus was selected for morphology comparison. Despite morphological differences four strains behaved in a similar manner during microbiological tests, displaying common preferences in growth media type, growth temperature and media $\mathrm{pH}$, survivability at various temperatures. Three tested media, with an increasing supply of nutrition compounds: LA, 2YT and TB, efficiently supported the investigated bacterial growth. LA medium was selected for further use. All further analyses were performed by inoculating media directly with the probiotics preparations to preserve the original species proportions and their possible interactions. Probiotic bacteria temperature growth optimum was determined within temperature range of $16-60^{\circ} \mathrm{C}$ for $48 \mathrm{hrs}$ Table 1 shows the temperature dependence of the Bacillus sp. probiotic growth. The population grew within the range of $18-56^{\circ} \mathrm{C}$, covering facultative psychrophiles or low-mesophilic to thermophilic range. Fig. 2 depicts the temperature-dependant morphological changes in the Bacillus sp. bacterial colonies, as at higher temperature the probiotics colonies tended to produce slime. It can be the result of proceeding membrane lipids variation and thermal denaturation of proteins, followed by cell lysis (Ahmed et al., 2008; Munna et al., 2015). Above $50^{\circ} \mathrm{C}$, colonies tended to lyse after $48 \mathrm{hrs}$ of prolonged incubation, thus $37-50^{\circ} \mathrm{C}$ range was optimal temperature for experiments. The ability to survive a long preincubation in media with various $\mathrm{pH}$ was tested, conditions were mimicked to reflect survivability in the environment, e.g., one relatively rich in trophic compounds, such as human gastro intestinal tract or soil, with $\mathrm{pH}$ varying to extreme values. Twenty four hour incubation in LB, pH 1-13 was conducted, followed by plating on LA, at pH 7.0 and $24 \mathrm{hrs}$ incubation at $37^{\circ} \mathrm{C}$. Table 1 presents that the examined probiotic Bacillus sp. survived prolonged incubation at $\mathrm{pH} 2-12$. The gastrointestinal tract $\mathrm{pH}$ of human and mammals below the stomach ranges from 4.5 to 8.5 , typically 7-8. These conditions are ideal for probiotic Bacillus sp. once they have survived in food fragments the passage through the stomach, with a pH 1-2. Considering the Bacillus sp. produce spores, the adaptation to colonize gastrointestinal tract is evident.

To estimate the survivability of Bacillus sp. probiotic during high temperature processing, involving extensive boiling, $100^{\circ} \mathrm{C}$ resistance was determined. Samples incubated in LB medium at $100^{\circ} \mathrm{C}$ were plated onto LA and incubated at $37^{\circ} \mathrm{C}$ for $24 \mathrm{hrs}$. Table 1 shows that boiling for 20-40 min resulted in slow decrease in population. On extended to boiling temperature for 18 hrs, probiotic bacteria still survived. This indicates that high temperature food processing does not eliminate probiotic Bacillus 
A

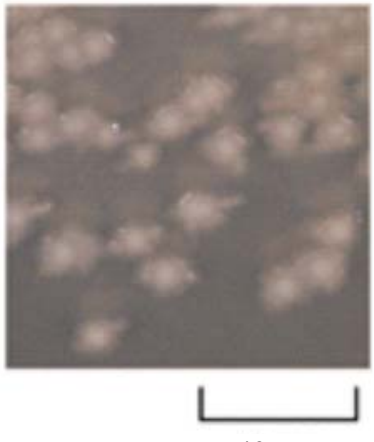

$10 \mathrm{~mm}$

E

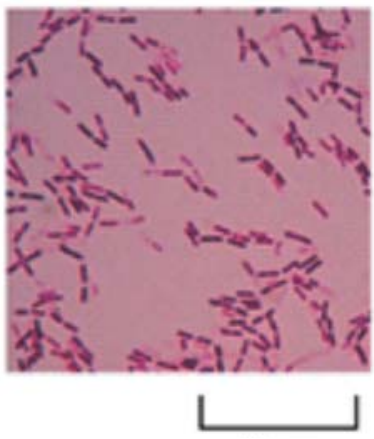

$40 \mu \mathrm{m}$

I

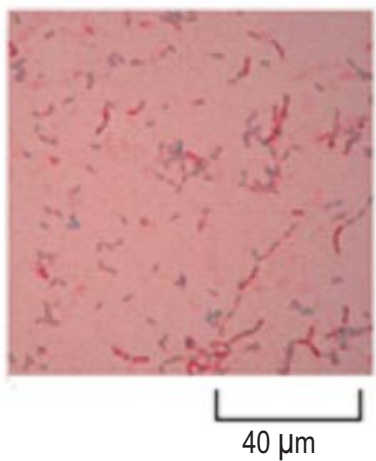

B

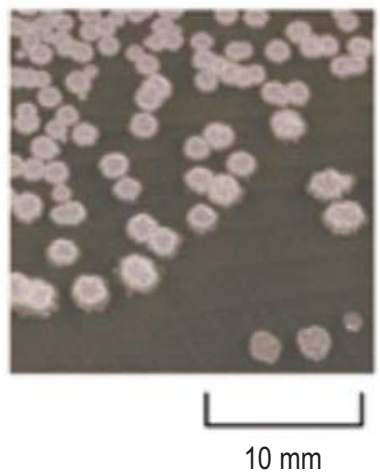

F

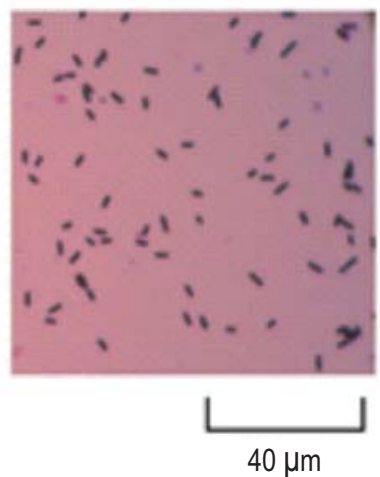

J

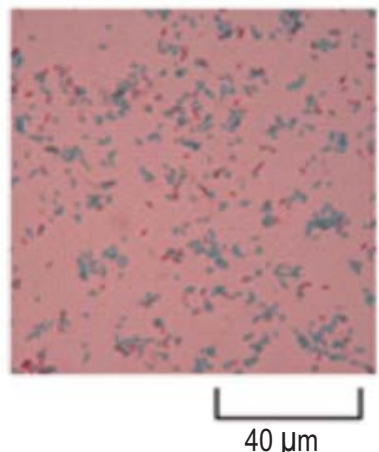

C

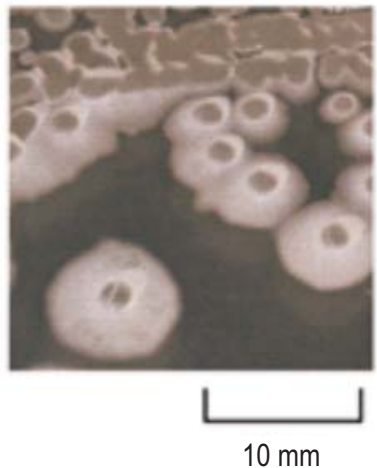

G

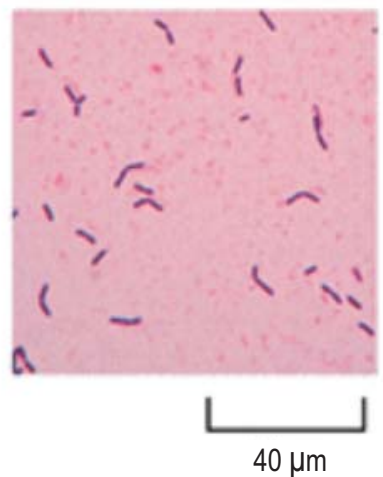

K

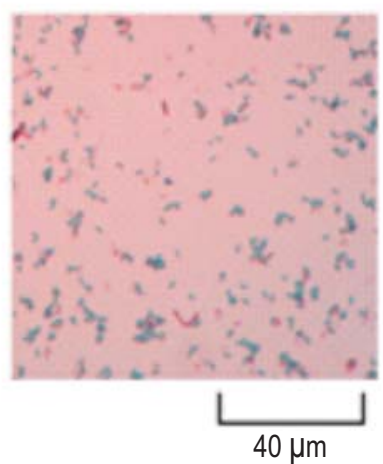

D

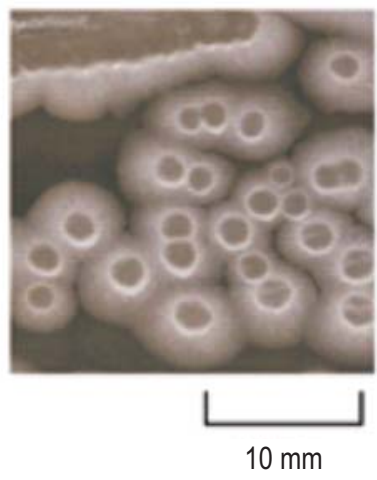

$\mathrm{H}$

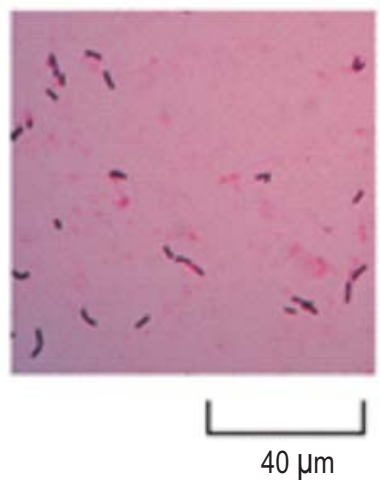

L

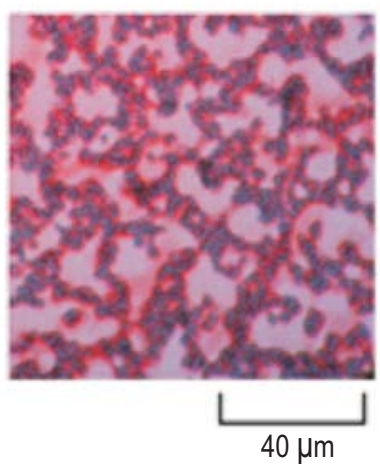

Fig.1 : Bacterial colony and cell morphology of Bacillus sp. isolated from the commercial probiotic preparation. Bacillus sp. colony growth on LA medium, after $24 \mathrm{hrs}$ of incubation at $37^{\circ} \mathrm{C}$, presenting MALDI-TOF identified species: (A)Bacillus subtilis, (B)Bacillus pumilus, (C)Bacillus vallismortis, (D)Bacillus mojavensis. Microscopic examination presenting detected Bacillus sp., subjected to Gram staining (E) Bacillus subtilis; (F) Bacillus pumilus; (G) Bacillus vallismortis; (H) Bacillus mojavensis; and to Wirtz's spores staining (I) Bacillus subtilis spores; (J)Bacillus pumilus spores; (K) Bacillus vallismortis spores; (L) Bacillus mojavensis spores

sp., allowing this beneficial microflora introduction to gastro intestinal tract The survivability of tested probiotic bacteria is an effect of producing spores. Fig. 1 shows green-stained spores within a microscopic preparations after Wirtz's spore staining of examined probiotic Bacillus sp.
Wide temperature growth range, survivability of extensive boiling and extreme $\mathrm{pH}$ confirm that probiotic Bacillus $\mathrm{sp}$. are adapted to the external environment with relatively low temperatures, also to the human gastrointestinal tract, as well as to survive conditions in compost piles, geothermal niches or other 
$17^{\circ} \mathrm{C}$

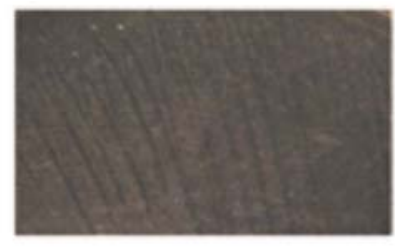

$37^{\circ} \mathrm{C}$

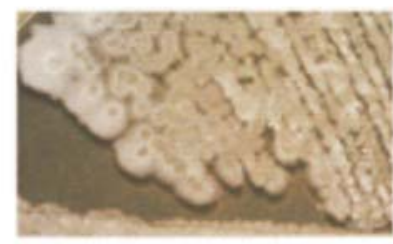

$55^{\circ} \mathrm{C}$

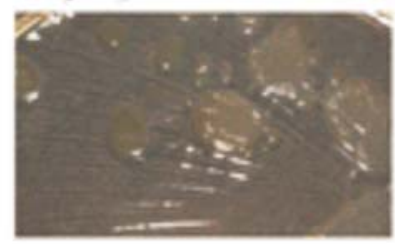

$18^{\circ} \mathrm{C}$

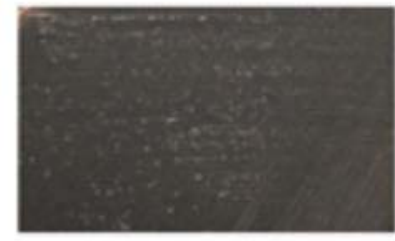

$45^{\circ} \mathrm{C}$

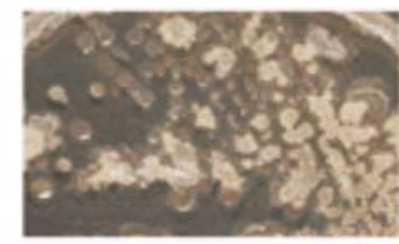

$56^{\circ} \mathrm{C}$

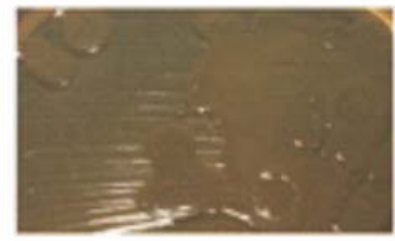

$20^{\circ} \mathrm{C}$

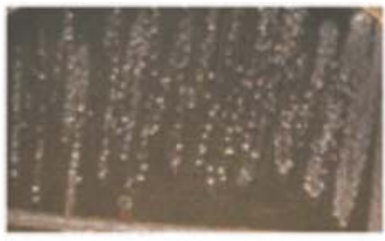

$51^{\circ} \mathrm{C}$

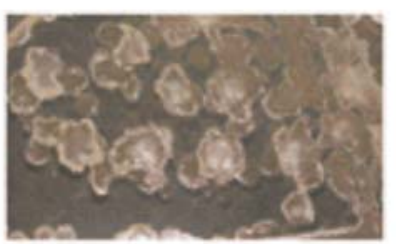

$57^{\circ} \mathrm{C}$

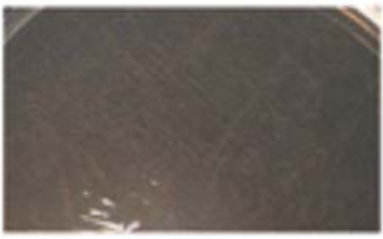

$30^{\circ} \mathrm{C}$

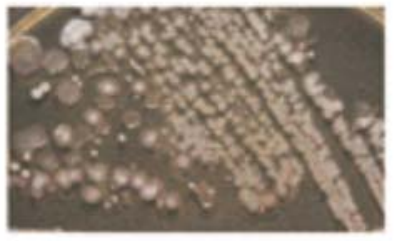

$53^{\circ} \mathrm{C}$

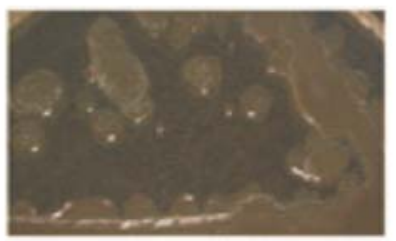

Fig.2 : Morphological changes of the temperature-dependant bacterial colonies of Bacillus species from the probiotic preparation. Bacteria grown for 48 hrs on LAmedium

harsh conditions. Considering the widespread presence of Bacillus sp. in the environment and that detailed cleaning or aseptic food preparation, decreasing or removing the natural microbes has become a practice only in very recent human history, it is certain that Bacillus sp. were ingested by humans since ages, being inseparable from human diet. Therefore, aerobically growing Bacillus sp. with spores capable of surviving in semi-anaerobic conditions of gastro intestinal tract, should be considered as beneficial commensals of human gastro intestinal tract, not soil microorganisms only. Studies have proved the advantages of $B$. subtilis to survive within the gastro intestinal tract (Hong et al., 2009). Analysing spores concentration of soil and gastrointestinal tract have revealed a high spore number found in human faeces, two orders of magnitude lower than in soil, which is too high, if acquired by food contamination.

The characterised Bacillus sp. probiotic mixture has a wide application in biotechnology. The range of Bacillus subtilis and Bacillus pumilus probiotics usage includes human-related applications, thus being a part of broader therapy e.g., as human dietary supplements (Cutting, 2011) or as surface biocontrol components for hospital-dedicated cleaning products (Vandini et al., 2014). Bacillus subtilis probiotics are proposed as biological control agents in the food-producing aquaculture (Verschuere et al., 2001), enhancing the growth by disease-resistance of cultured shrimps or tiger grouper (Cutting, 2011; Yasin, 2016). On the other hand, the composition of Bacillus subtilis and its close relatives $B$. mojavenisis and $B$. vallismortis, together with Bacillus pumilus, will potentially serve for an environmental remediation procedures, such as wastewater treatment and decomposition of solid organic wastes. These may include high temperature processes or pre-treatments with high/low pH or boiling. Bacillus $\mathrm{sp}$. are well known biotechnological sources of extracellularly secreted hydrolase enzymes (Priest, 1977; Barros et al., 2013), mostly heat-resistant or thermostable amylases, lipases or proteases. Currently, Bacillus subtilis and Bacillus pumilus origin xylanase enzyme (Irfan et al., 2012; Battan et al., 2007,Acharya and Shilpkar, 2016) is being applied for the industrial release of sugars from plants during lignocellulosis biomass pretreatment or in saccharification of food technology wastes

Commercial Bacilox@ probiotics preparation consisted of four sporulating species: Bacillus subtilis, Bacillus pumilus, Bacillus mojavensis and Bacillus vallismortis. The bacteria exhibited growth temperature range of $18-56^{\circ} \mathrm{C}$, boiling and $\mathrm{pH}$ extremes resistance. These probiotics are advantageous for bimodal existence in the environment and gastrointestinal tract, having a vast potential in biotechnological applications.

\section{Acknowledgments}

This work was supported by GRUPA INCO S.A., ul. Wspolna 25, 00-519 Warsaw, Poland, NCBiR grant 
POIG.01.04.00-02-81/13. Marta Skowron is appreciated for critical reading of the manuscript and English corrections.

\section{References}

Acharya, K.P. and P. Shilpkar: Production, partial purification and characterization of xylanase using Nicotiana tabacum leaf dust as substrate. J. Environ. Biol., 37, 297-303 (2016).

Ahmed A., A. N. Sabri and S. Hasnain: Effect of varying temperature on growth, morphology and soluble protein content of div IV and div V mutant strains of Bacillus subtilis. Afr. J. Biotechnol., 7, 1505-1511 (2008).

Azarko, J. and U. Wendt: Identification of microorganisms - comparison of biochemical and mass spectrometry method. Diagn. Lab., 47, 409-417 (2011).

Barros, F.F.C., A.P.R. Simiqueli, C.J. de Andrade and G.M. Pastore: Production of enzymes from agroindustrial wastes by biosurfactant-producing strains of Bacillus subtilis. Biotechnol. Res. Int., id103960, doi.org/10.1155/2013/103960, (2013).

Bartholomew, J.W. and T. Mittwer: The Gram Stain. Bacteriol. Rev.,16, 129 (1952).

Battan, B., S. Jitender, S.S. Dhiman and R.C. Kuhad: Enhanced production of cellulase-free thermostable xylanase by Bacillus pumilus ASH and its potential application in paper industry. Enzyme Microb. Tech., 41, 733-739 (2007).

Berkeley, R.M., N.L. Heyndrickx and P. De Vos: Applications and systematics of Bacillus and relatives. Oxford. Wiley-Blackwell (2008).

Castellazzi, A.M., C. Valsecchi, S. Caimmi, A. Licari, A. Marseglia, M.C. Leoni, D. Caimmi, M. M. del Giudice, S. Leonardi, M. La Rosa and G.L. Marseglia: Probiotics and food allergy. Ital. J. Pediatr., 39, 47 (2013)

Cutting, S.M.: Bacillus probiotics. Food Microbiol., 28, 214-220 (2011)

Earl, A.M., M. Eppinger, W.F. Fricke, M.J. Rosovitz, D.A. Rasko, S. Daugherty, R. Losick, R. Kolter and J. Ravel: Whole-genome sequences of Bacillus subtilis and close relatives. J. Bacteriol., 194, 2378-2379 (2012).

Hamouda, T., A.Y. Shih and J.R. Baker: A rapid staining technique for the detection of initiation of germination of bacterial spores. Lett. Appl. Microbiol., 34, 86-90 (2002).

Hong, H.A., R. Khaneja, N.M.K. Tam, A. Cazzato, S. Tan, M. Urdaci, A. Brisson, A. Gasbarrini, I. Barnes and S.M. Cutting: Bacillus subtilis isolated from the human gastrointestinal tract. Res. Microbiol., 160,134-143 (2009).

Irfan, M., M. Nadeem, Q. Syed and S. Baig: Effect of medium composition on xylanase production by Bacillus subtilis using various agricultural wastes. American-Eurasian J. Agric. Environ. Sci., 12, 561-565 (2012).

Jenny, B.F., H.J. Vandijk and J.A. Collins: Performance and fecal flora of calves fed a Bacillus subtilis concentrate. J. Dairy Sci.,74, 19681973 (1991).

La Ragione, R.M. and M.J. Woodward: Competitive exclusion by Bacillus subtilis spores of Salmonella enterica serotype Enteritidis and Clostridium perfringens in young chickens. Vet. Microbiol., 94, 245-256 (2001).
La Ragione, R.M., G. Casula, S.M. Cutting and M.J. Woodward: Bacillus subtilis spores competitively exclude Escherichia coli 078:K80 in poultry. Vet. Microbiol., 79, 133-142 (2001).

La Rosa, M., G. Bottaro, N. Gulino, F. Gambuzza, F. Di Forti, G. Inì and E. Tornambè: Prevention of antibiotic-associated diarrhea with Lactobacillus sporogens and fructo-oligosaccharides in children. A multicentric double-blind vs placebo study. Minerva Pediatr., 55, 447-452 (2003).

Meroni, P.L., R. Palmieri, W. Barcellini, G. De Bartolo and C. Zanussi: Effect of long term-treatment with $B$. subtilis on the frequency of urinary tract infections in older patients. Chemiotherapia, 2, 142144 (1983).

Munna, Md.S., J. Tahera, Md. M.H. Afrad, I.T. Nur and R. Noor: Survival of Bacillus spp. SUBB01 at high temperatures and a preliminary assessment of its ability to protect heat-stressed Escherichia coli cells. BMC Res. Notes, 8, 637 (2015).

Plaza-Diaz, J., C. Gomez-Llorente, L. Fontana and A. Gil: Modulation of immunity and inflammatory gene expression in the gut, in inflammatory diseases of the gut and in the liver by probiotics. World J. Gastroenterol., 20, 15632-15649 (2014).

Prazdnova, E.V., V.A. Chistyakov, M.N. Churilov, M.S. Mazanko, A.B. Bren, A. Volski and M.L. Chikindas: DNA-protection and antioxidant properties of fermentates from Bacillus amyloliquefaciens B-1895 and Bacillus subtilis KATMIRA1933. Lett. Appl. Microbiol., 61, 549-54 (2015).

Priest, F.G.: Extracellular enzyme synthesis in the genus Bacillus. Bacteriol. Rev., 41, 711-753 (1977).

Quigley, E.M.M.: Prebiotics and Probiotics; Modifying and mining the microbiota. Pharmacol. Res. , 61, 213-218 (2010).

Roberts, M.S., L. K. Nakamura and F.M. Cohan: Bacillus vallismortis sp. nov., a close relative of Bacillus subtilis, isolated from soil in Death Valley, California. Int. J. Syst. Bacteriol., 46, 470-475 (1996)

Roberts, M.S., L.K. Nakamura and F.M. Cohan: Bacillus mojavensis sp. nov., distinguishable from Bacillus subtilis by sexual isolation, divergence in DNA sequence, and differences in fatty acid composition. Int. J. Syst. Bacteriol., 44, 256-264 (1994).

Thirabunyanon, M. and N. Thongwittaya: Protection activity of a novel probiotic strain of Bacillus subtilis against Salmonella enteritidis infection. Res. Vet. Sci., 93, 74-81 (2011).

Urgesi, R., C. Casale, R. Pistelli, G.L. Rapaccini and I. de Vitis: A randomized double-blind placebo-controlled clinical trial on efficacy and safety of association of simethicone and Bacillus coagulans (Colinox®) in patients with irritable bowel syndrome. Eur. Rev. Med. Pharmacol.Sci., 18, 1344-1353 (2013).

Vandini, A., R. Temmerman, A. Frabetti, E. Caselli, P. Antonioli, P.G. Balboni, D. Platano, A. Branchini and S. Mazzacane: Hard surface biocontrol in hospitals using microbial-based cleaning products. PLOS ONE, 9, e108598, doi:10.1371/journal.pone.0108598 (2014).

Verschuere, L., G. Rombaut, P. Sorgeloos and W Verstraete: Probiotic bacteria as biological control agents in aquaculture. Microbiol. Mol. Biol. Rev., 64, 655-671 (2001).

Yasin, I.M., N.F. Razak, F.M.I. Natrah and S.A. Harmin: Selection and evaluation of Malaysian Bacillus spp. strains as potential probiotics in cultured tiger grouper (Epinephelus fuscoguttatus). J. Environ. Biol., 37, 791-800 (2016). 